\title{
MODEL PEMBERDAYAAN HUKUM LINGKUNGAN RELIGIUS - KOSMIK SEBAGAI UPAYA PELESTARIAN FUNGSI LINGKUNGAN HIDUP
}

\author{
Mella Ismelina Farma Rahayu \\ Dosen Fakultas Hukum Universitas Islam Bandung, Jl. Ranggagading No. 8 Bandung 40116, Telp: \\ 022-4203368 ext. 129, Fax: 022-4211506, Hp: 081572993969, E-mail: \\ mellaismelina@yahoo.com
}

\section{Anthon F. Susanto}

Dosen Fakultas Hukum Universitas Pasundan, Jl. Lengkong Besar No. 68 Bandung 40261, Telp: $022-$ 4262226, Fax: 022-421 7340, Hp: 08121 4063360, E-mail: anthon.aiki@gmail.com

\section{Liya Sukma Muliya}

Dosen Fakultas Hukum Universitas Islam Bandung, Jl. Ranggagading No. 8 Bandung 40116, Telp: 022-4203368 ext. 129, Fax: 022-4211506, Hp: 081320575116, E-mail: muliyasukma@yahoo.com

\begin{abstract}
ABSTRAK
Tulisan ini bersumber dari hasil penelitian yang berusaha untuk mengangkat nilai-nilai kearifan budaya Sunda dalam upaya pelestarian fungsi lingkungan hidup dengan membangun sebuah model pemberdayaan hukum lingkungan religuis-kosmik berbasis Daerah Aliran Sungai (DAS) berdasarkan konsepsi budaya Sunda. Model ini dipandang perlu karena lebih mengedepankan relasi dan keseimbangan antara keadilan ekologis dan keadilan sosial, lebih mengakomodasi kesetaraan dan keseimbangan antara kesejahteraan masyarakat dan keharmonisan lingkungan hidup. Dalam bahasan ini digambarkan pula bagaimana interaksi manusia dengan lingkungan hidupnya dengan gambaran objektif masyarakat desa Ciomas dalam menerapkan nilai-nilai budaya leluhurnya dalam pelestarian fungsi lingkungan hidup dan bagaimana upaya mengimplementasikan nilai-nilai kearifan budaya Sunda tersebut dalam perumusan pembangunan hukum lingkungan di Indonesia agar lebih berkarakteristik ke Indonesiaan.
\end{abstract}

Kata Kunci: Lingkungan, Budaya Sunda, Relijius Kosmik. 


\begin{abstract}
This paper is derived from the results of research that seeks to elevate the values of Sundanese cultural wisdom in environment conservation efforts by building a model of environmental law with religious empowerment-based cosmic Watershed (DAS) based on the conception of Sundanese culture. This model emphasizes deemed necessary because the relationship between justice and ecological balance and social justice, equality and better accommodate a balance between social welfare and environmental harmony.It is also illustrated how human interaction with the environment with the objective picture of rural communities in implementing value if Ciomas ancestral cultural values in environment conservation efforts and how to implement the values of the Sundanese cultural wisdom in the formulation development of environmental law in Indonesia to be more characteristic of Indonesia.
\end{abstract}

Keywords: Environmental, Sundanese Culture, Cosmic Religious. 

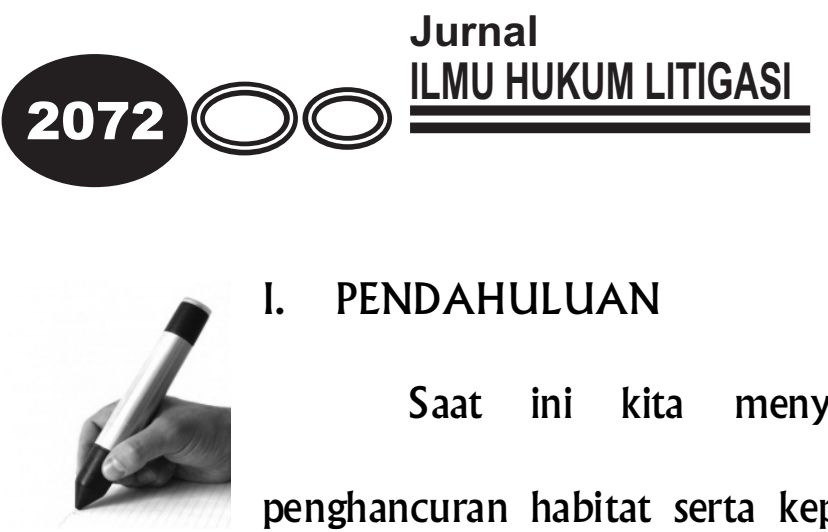

\section{PENDAHULUAN}

Saat ini kita menyaksikan terdegradasinya lingkungan, penghancuran habitat serta kepunahan spesies yang diakibatkan oleh perilaku manusia yang konsumtif dan cenderung serakah dengan hanya mementingkan kelangsungan hidup mereka semata, misalnya saja isu pembangunan lebih fokus kepada kesejahteraan bagi segelintir atau sekelompok orang, namun jauh dari upaya untuk menciptakan keadilan ekologis. Pembangunan lingkungan dirasakan sangat timpang, karena lebih menitikberatkan pada aspek manusia (anthroposentris), dari pada lingkungannya (ekosistem). Hal yang sama terjadi dalam strategi kebijakan negara menyangkut pembangunan hukum lingkungan di Indonesia sebagaimana tertuang dalam ketentuan UndangUndang Pengelolaan Lingkungan Hidup, di samping sangat (berkarakter) formalistik, hirarkhis-dualistik, juga sentralistik, yang seluruhnya didukung oleh rasionalisme-metode ilmiah (scientisme) dan teknologi modern dari Barat. Cara pandang Barat pun telah mempengaruhi perkembangan pembangunan hukum lingkungan di Indonesia yang mengakibatkan pembangunan hukum lingkungan lebih berorientasi industrialis dan konsumtif (developmentalism) (Schoorl, 1980), dan cenderung anti ekologis (Capra, Fritjof, 2004:100). Penggunaan metode ilmiah dan pikiran rasional analitis telah menimbulkan sikap yang anti ekologis demikian pula dengan pertumbuhan ekonomi (konsumtif) dan teknologi yang tak terhingga telah menimbulkan gangguan terhadap keseimbangan alam, 
dan lambat laun menyebabkan kerusakan lingkungan yang luar biasa, seperti yang dikatakan oleh Gunnar Myrdal, bahwa "teori-teori dan konsep pembanguan Barat jika di terapkan akan menimbulkan konsekuensi-konsekuensi serius (Slamet Sutrisno, 2004:100).

Lebih jauh, kebijakan pembangunan lingkungan hanya memihak dan menguntungkan segolongan orang atau pemangku kekuasaan tertentu. yang mengakibatkan masyarakat kecil termarjinalkan, semakin dirugikan dan menjadi korban (victims) dari kebijakan pembangunan lingkungan yang tidak berpihak kepada kepentingan masyarakat dan lingkungan.

Orientasi pembangunan hukum lingkungan pada akhirnya terdegradasi pada titik terendah dalam pembangunan hukum yang hanya mengedepankan aspek peraturan-perundang-undangan dan kebijakan negara, melalui model pengelolaan yang selama ini bersifat atur dan awasi (command and control). Kebijakan pembangunan hukum lingkungan masih belum melihat peluang nilainilai kearifan lokal yang lebih memiliki relasi religius-kosmik menyangkut relasi antara manusia dan lingkungannya. Pembangunan hukum lingkungan dibangun dengan landasan dominasi negara dalam perumusan kebijakan atau peraturan dan pelaksanaannya di bidang pengelolaan lingkungan hidup. Keterlibatan masyarakat dan pemberdayaan masyarakat dalam pembangunan dan pengelolaan lingkungan hidup belum maksimal sehingga sistem pengelolaan dan pembangunan hukum lingkungan menjadi tidak partisipatif dan holistik. Lebih jauh kebijakan yang 


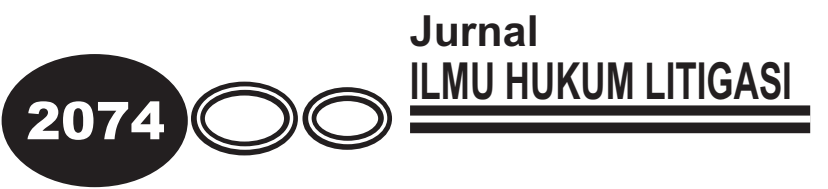

dirumuskan tidak selaras dengan potensi sumber daya lingkungan dan masyarakat nya. Kondisi demikian itu, menjadikan hukum lingkungan belum mampu mengakomodasi penyelesaian problem lingkungan yang terjadi dalam masyarakat, memberikan kesejahteraan pada masyarakat secara keseluruhan, dan belum mampu memberikan keseimbangan antara keadilan sosial dengan keadilan ekologis.

Pembangunan hukum lingkungan yang ideal adalah yang mampu menciptakan relasi kesetaraan antara manusia dan lingkungan. Oleh karena itu, perlu upaya mengkonstruksi sebuah model alternatif pemberdayaan hukum lingkungan yang lebih merespon nilai-nilai keadilan sosial dan keadilan ekologis, lebih mengakomodasi kesetaraan dan keseimbangan antara kesejahteraan masyarakat dan keharmonisan lingkungan hidup, melalui formulasi model pemberdayaan hukum lingkungan yang religius-kosmik berdasar kearifan budaya lokal dalam hal ini adalah kearifan budaya Sunda.

Pembahasan dalam tulisan ini menitik beratkan pada pembahasan nilainilai kearifan budaya Sunda dalam pelestarian fungsi lingkungan hidup dan gambaran kondisi objektif masyarakat desa Ciomas dalam interaksi mereka dengan lingkungannya yang masih menerapkan dan menghormati niai-nilai leluhurnya dalam upaya pelestarian fungsi lingkungan hidup. Kearifan budaya Sunda mengajarkan bahwa manusia adalah bagian dari alam semesta, sehingga manusia harus taat terhadap aturan alam semesta yang diyakini sebagai aturan 
atau hukum dari Sang Pencipta. Nilai-nilai tersebut dicoba untuk dijadikan landasan bagi formulasi model pemberdayaan hukum lingkungan yang religiuskosmik.

Berdasarkan uraian di atas, maka permasalahan diidentifikasikan sebagai berikut:

1. Bagaimanakah interaksi manusia dan lingkungan hidup berdasarkan kearifan budaya Sunda.

2. Sejauhmanakah konsep pelestarian fungsi lingkungan hidup berdasarkan kearifan budaya Sunda dapat dijadikan sebagai landasan formulasi model pemberdayaan hukum lingkungan religius-kosmik.

3. Bagaimanakah upaya pelestarian fungsi lingkungan hidup di Desa Ciomas Kecamatan Panjalu Kabupaten Ciamis.

\section{METODE PENELITIAN}

Permasalahan yang telah diidentifikasikan tersebut akan dipecahkan dengan menggunakan metode penelitian kualitatif karena fokus dari tulisan ini adalah kajian hubungan antara manusia dan budaya nya. Sifat dari penelitian kualitatif adalah tidak melakukan perhitungan-perhitungan dalam melakukan justifikasi epistemologis. Penelitian ini juga merupakan penelitian fenomenologis, interpretatif dan juga ekologis, dan deskriptif (Bogdan Robert C. \& Sari Knopp Biklen, $1982: 3)$. Metode penelitian tersebut digunakan karena mampu 


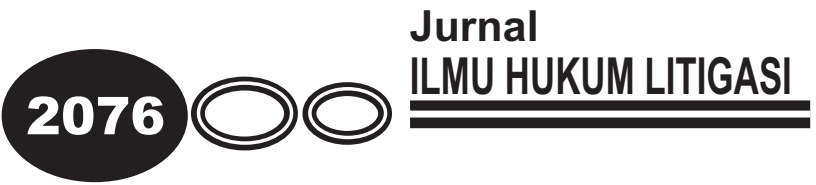

memberikan penjelasan secara utuh tentang hakekat yang ditelitinya (Bogdan Robert C. \& Taylor Steven J, 1993:10).

Jenis data yang dikumpulkan dalam penelitian ini adalah data sekunder dan data data primer yang diperoleh dari penelitian lapangan. Data sekunder yang dikumpulkan adalah berupa data dokumen, teks atau karya-karya ilmiah yang relevan dengan persoalan yang diteliti, sedangkan data primer diperoleh dari hasil wawancara dengan Kabid Fasilitasi Standar Pelayanan Minimal Kementerian Lingkungan Hidup, ketua dan anggota Komunitas Peduli Lingkungan Hidup Bela Alam Nusantara (KPLH BELANTARA), Ketua dan anggota Dewan Pemerhati Kehutanan Lingkup Tatar Sunda (DPKLTS), dan Masyarakat Komunitas Adat Ciomas (KANCI).

Teknik pengumpulan data dilakukan melalui telaah dokumen untuk memperoleh data sekunder, sedangkan untuk perolehan data primer dilakukan teknik pengumpulan data melalui partisipasi observasi dan wawancara secara mendalam (indepth). Sumber data primer tidak bersifat tunggal tetapi beragam dan diperoleh melalui informan kunci (key-informan) dengan model bola salju (snowball) yang terus meluas disesuaikan dengan kebutuhan, arah dan tujuan penelitian. Sesuai dengan karakteristik penelitian kualitatif, maka dalam penelitian ini, peneliti menjadi instrument (alat pengumpul data) utama.

Pengecekan data akan dilakukan dengan model "triangulasi data" yaitu triangulasi yang berkaitan dengan penggunaan beragam sumber data dalam suatu 
penelitian (Janesick, Valerie J., 1994). Triangulasi digunakan untuk klarifikasi terhadap sejumlah data yang telah dikumpulkan guna memperoleh pemahaman yang lebih mendalam tentang apa yang dikaji. Menurut Agus Salim, triangulasi bukan merupakan alat atau strategi untuk pembuktian, tetapi hanya sebagai alternatif terhadap pembuktian (Agus Salim, 2001:6-7).

Menurut Denzin \& Lincoln, triangulasi adalah merefleksikan suatu usaha untuk mendapatkan pemahaman yang lebih mendalam tentang fenomena yang dikaji, karena realitas sesungguhnya tidak akan pernah terungkap. Konsep triangulasi didasarkan pada asumsi bahwa setiap bias yang melekat pada sumber data, peneliti maupun metode akan dapat dinetralisir apabila digunakan dalam keterkaitannya dengan sumber data dan metode yang lain (Denzin, Norman K. dan Yvonna S. Lincoln, 1994:1). Metode yang dikombinasikan merupakan satu cara yang dipakai oleh peneliti dalam konteks pengumpulan dan analisis data (Antonius Birowo, 2004:6).

Analisis data dilakukan melalui proses interpretasi, koherensi intern, komparasi dan heuristik. Interpretasi dilakukan dengan tujuan ingin menangkap makna dari data yang telah diperoleh dan kemudian dilakukan evaluasi kritis sehingga diperoleh pandangan alternatif yang lebih tepat. Koherensi intern, dilakukan untuk melihat keterkaitan semua unsur-unsur dalam berbagai aspek yang diteliti guna menemukan unsur-unsur yang sentral dan unsur yang marginal, sedangkan komparasi dilakukan untuk membandingkan hasil kajian dengan teori- 


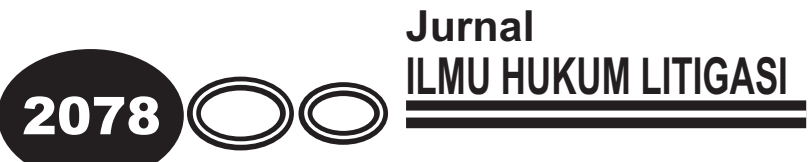

teori lainnya, juga membandingkan dengan pandangan-pandangan lainnya sehingga diperoleh konsepsi dasar yang termuat dalam data yang dikaji. Heuristik, dilakukan guna memperoleh pemahaman yang lebih luas dan baru terkait data penelitian sehingga dapat tersaji model alternatif pemberdayaan hukum lingkungan yang dapat dijadikan landasan bagi perumusan kebijakan pembangunan hukum lingkungan di Indonesia.

\section{HASIL PENELITIAN DAN ANALISIS}

A. Konsep Interkasi Manusia dan Lingkungan Hidup berdasarkan Kearifan Budaya Sunda

Dalam pembahasan sub bab ini, kearifan budaya lokal yang dikaji adalah menyangkut pengetahuan asli masyarakat Sunda khususnya di Desa Ciomas Kecamatan Panjalu Kabupaten Ciamis dalam interaksi mereka dengan lingkungannya terutama dalam upaya pemulihan dan pelestarian fungsi lingkungan hidup.

Berdasarkan Kearifan Budaya Sunda, alam dan manusia memiliki hukum ruang dan waktu yang sama atau memiliki substansi yang sama, perbedaannya hanya pada pengaktualisasian yang dilakukan oleh manusia itu sendiri. Jika kita kaji banyak peristilahan yang ada pada manusia ada pula peristilahannya dalam konteks alam semesta, contohnya kata "sirah", "hulu", “dampal suku” dan lain sebagainya. 
Berikut ini disajikan gambar terkait hal tersebut (Rahmat, KPLH Belantara, 2010):

Terkait ruang atau kawasan, kearifan budaya Sunda membagi ke dalam tiga ruang atau kawasan yaitu kawasan konservasi / leuweung larangan, kawasan penyangga atau pelindung/ leuweung tutupan dan kawasan budidaya atau produksi/ leuweung baladahan atau garapan.

Kawasan konservasi / leuweung larangan adalah kawasan titipan yang tidak boleh diganggu, harus dibiarkan sesuai aslinya untuk pemenuhan kebutuhan bathin.

Kawasan penyangga atau pelindung/ leuweung tutupan adalah kawasan yang boleh dibuka pada saat tertentu dan dimanfaatkan oleh 


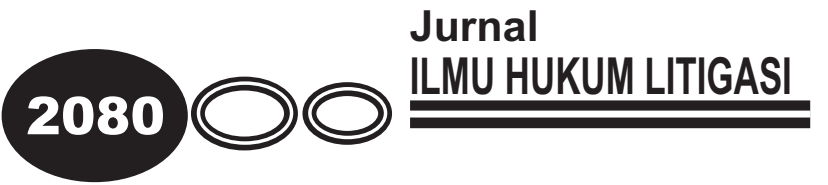

manusia secara terbatas. Kawasan ini berfungsi untuk pelindung atau kawasan cadangan bagi leuweung larangan dan leuweung baladahan.

Kawasan budidaya atau produksi/ leuweung baladahan atau garapan adalah kawasan yang boleh dibuka atau digarap, dibudidayakan atau diproduksi tetapi tidak melampaui daya dukung lingkungan dan daya tampung lingkungan guna pemenuhan kebutuhan lahir manusia sebagai penyeimbang kebutuhan bathiniyah manusia. Kawasan ini biasanya diperuntukan bagi pertanian, perkebunan, perumahan, dan lain-lain.

Lebih lanjut, berdasarkan sistematika kearifan budaya Sunda ada relasi antara manusia dengan alam semesta (hewan, tumbuhan dan lain-lain) dalam pola yang dikatakan sebagai TRI TANGTU. Dimana interaksi alam dengan manusia menghasilkan sebuah pengalaman; kemudian interkasi alam, manusia dan pengalaman menghasilkan sebuah ilmu; dan interaksi alam, manusia, pengalaman dan ilmu menghasilkan sebuah amal. Dengan demikian gabungan antara amal, ilmu dan pengetahuan adalah ALAM. Terkait hal tersebut dapat terlihat dalam bagan berikut ini (Rahmat, KPLH Belantara, 2010): 
Berdasarkan uraian di atas, tergambarkan bahwa terdapat keterkaitan yang erat antara relasi manusia dan lingkungan hidup. Manusia adalah bagian yang tidak terpisahkan dari unsur lingkungan hidup lainnya. Apa yang ada di struktur manusia ternyata merupakan gambaran yang ada di struktur alam. Hal ini menandakan bahwa tidak ada hubungan subordinat antara manusia dan lingkungan hidup, dalam pemaknaan bahwa manusia tidak berada pada posisi yang lebih atas dan dominan dibandingkan dengan unsur lingkungan hidup lainnya. Dalam posisi ini manusia memiliki etika ketika berinteraksi dengan lingkungan hidupnya. 


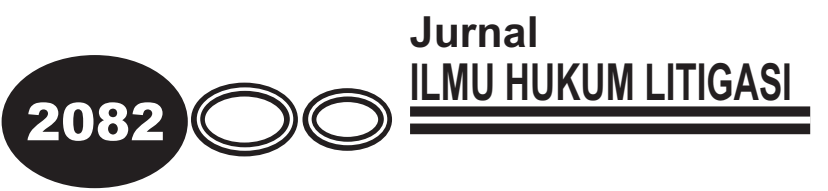

B. Konsep Pelestarian Fungsi Lingkungan Hidup berdasarkan Kearifan Budaya Sunda Sebagai Landasan Formulasi Model Pemberdayaan Hukum Lingkungan Religius-Kosmik

Aktivitas pelestarian fungsi lingkungan hidup berdasarkan kearifan budaya Sunda (KBS) dilakukan atas pemahaman bahwa "Sunda kabagean memeres jaman," dan aktivitas "ngaberakeun". "Memeres" memberikan makna memulihkan atau memperbaiki atau mengembalikan kepada asalnya, sedangkan ngaberakeun, adalah aktivitas meninggalkan satu kawasan dengan tujuan pemulihan daya dukung dan daya tampung lingkungan dan akan kembali lagi jika daya dukung lingkungan dan daya tampung lingkungan telah pulih kembali.

Terkait pelaksanaan pelestarian fungsi lingkungan hidup berdasarkan kearifan budaya Sunda terbagi ke dalam tiga tahapan yaitu (Mella Ismelina FR dkk, 2010; 97) : tahapan kabataraan, tahapan kadewaan dan tahapan karatuan.

Tahapan kabataraan merupakan tahapan awal dimana dalam tahap ini dilakukan hal-hal yang pokok bagi langkah-langkah berikutnya dalam pelestarian fungsi lingkungan hidup yaitu penetapan tata wilayah yang menetapkan batasan leuweung larangan, leuweung tutupan, dan leuweung baladahan. 
Tahap kedua adalah tahapan kadewaan yang dilakukan dalam masa tiga tahun. Tahap kadewaan ini merupakan tahapan masa-masa pembelajaran dalam tahap ini ditentukan pula lokasi percobaaan. Target yang diharapkan dalam masa kadewaan adalah diperolehnya proyeksi kasaliraan, yaitu terbangunnya pemahaman dan kekuatan individu pada suatu komunitas masyarakat dalam ruang lingkup pangauban atau daerah aliran sungai (DAS). Kemudian proyeksi kabalareaan, yaitu terbangunnya kekuatan komunal masyarakat dalam ruang lingkup pangauban dan terakhir adalah proyeksi kabuanaan, yaitu terbangunnya kekuatan masyarakat dalam ruang lingkup pangauban.

Tahap ketiga adalah tahapan karatuan, yaitu tahapan untuk melakukan pemulihan secara menyeluruh sesuai dengan hasil dari penetahapan tahap kabataraan.

Dalam aktivitas pelestarian fungsi lingkungan hidup ditetapkanlah apa yang dinamakan (Mella Ismelina FR dkk, 2010: 61-65): tata wilayah yang menetapkan tiga kawasan yaitu kawasan /leuweung larangan, kawasan baladahan dan kawasan tutupan. Kemudian tata wayah (Pranata Mangsa) yang menetapkan sistem perhitungan waktu berkaitan dengan aktivitas pengelolaan di tiga kawasan yaitu kawasan larangan, tutupan dan baladahan serta penetapan tata lampah yang merupakan penetapan aktifitas atau 


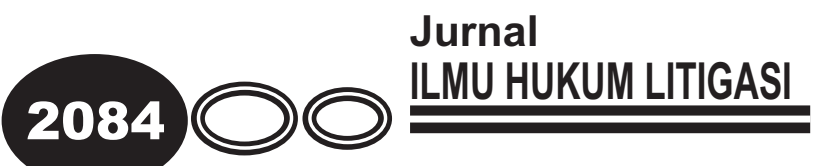

berkegiatan dalam pelestarian fungsi lingkungan hidup yang pelaksanaannya terkait dengan tata wilayah dan tata wayah.

Terkait analisis ekonomi dari pemanfaatan ruang berdasarkan konsep Daerah Aliran Sungai (DAS), Kearifan Budaya Sunda telah menetapkan rasio prosentase pemanfaatan ruang yaitu bagian hilir terbagi peruntukan untuk nabati dan hewani perbandingannya adalah $30: 70$; bagian tengah perbandingan peruntukan nabati dan hewani adalah $50: 50$; dan bagian hulu perbandingan peruntukan nabati dan hewani adalah 70:30. Berikut ini adalah bagan terkait hal tersebut (Rahmat, KPLH Belantara, 2010): 
C. Upaya Pelestarian Fungsi Lingkungan Hidup Di Desa Ciomas Kecamatan Panjalu Kabupaten Ciamis

Revitalisasi nilai-nilai kearifan budaya sunda adalah salah satu upaya yang dapat dilakukan dalam menangani permasalahan lingkungan dewasa ini. Oleh karena itu, bahasan dalam sub bab ini lebih difokuskan pada aktivitas masyarakat desa Ciomas dalam upaya pelestarian fugsi lingkungan hidup. Aktivitas tersebut dilakukan oleh masyarakat di Desa Ciomas didasarkan pada kesadaran dan kemauan untuk menerapkan kembali nilai-nilai pengetahuan luhur melalui implementasi kearifan lokal dalam pengelolaan DAS yang dijadikan acuan oleh masyarakat pemegang tradisi (masyarakat adat sunda) dan terbukti relevan dalam menjaga keberlanjutan kehidupan.

Upaya pelestarian fungsi lingkungan dan bagaimana masyarakat Desa Ciomas berinteraksi dengan lingkungan hidupnya sudah didasari pada kearifan lokal yang berkarakteristik magic-kosmik. Sonny Keraf dalam bukunya "Etika Lingkungan," (Sonny Keraf, 2002) mengatakan bahwa kearifan tradisional adalah semua bentuk pengetahuan, keyakinan, pemahaman, dan wawasan serta adat kebiasaan atau etika yang menuntut perilaku manusia dalam kehidupan di dalam komunitas ekologis. Seluruh kearifan tradisional ini dihayati, dipraktekkan, diajarkan, dan diwariskan dari satu generasi ke generasi selanjutnya. Sekaligus juga kearifan itu membentuk pola perilaku 


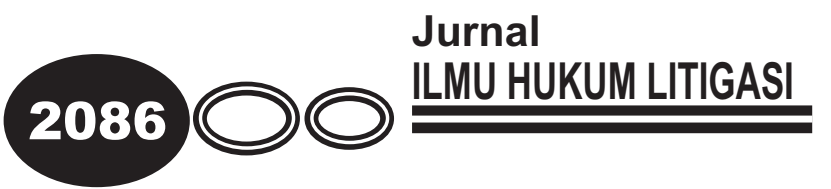

manusia sehari-hari, baik terhadap sesama manusia maupun terhadap alam yang gaib.

Cara pandang dan tata kehidupan masyarakat adat telah membuktikan keberhasilan dalam menyelamatkan alam dan lingkungan hidup. Hal tersebut terjadi di masyarakat Desa Ciomas. Saat ini warga Ciomas berupaya untuk tetap menjaga adat istiadat yang pada dasarnya adalah kearifan lokal yang mereka miliki. Dalam interaksi manusia dan lingkungan, masyarakat Desa Ciomas selalu berpatokan pada Daerah Aliran Sungai (DAS) atau Pangauban, karena DAS melambangkan aspek bathin, dimana air merupakan sumber kehidupan makhluk, simbol ketenangan, air sebagai suatu unsur alam yang menjadi bahan dasar terbentuknya tubuh dan jiwa manusia, air menjadi sumber bagi kebutuhan hidup manusia. Dalam kearifan lokal, air menjadi titik pusat kehidupan (sanghyang udel) layaknya raga yang berpusat pada perut di tengah-tengah. Mata air sendiri dalam kearifan Sunda akan disebut sebagai sanghyang pertiwi karena keluar dari perut bumi.

Masyarakat Desa Ciomas menetapkan leuweung larangan (hutan terlarang) di gunung Sawal sebagai tempat yang harus betul-betul dijaga kelestarian fungsi lingkungannya dan dipatuhi tata kramanya sebagai bagian dari sistem. Terkait pemahaman lingkungan dalam Adat Sunda atau masyarakat Sunda memiliki falsafah, bahwa antara manusia dan alam merupakan sebuah bagian yang menyatu. Manusia merupakan sebuah bagian 
dari sub sistem alam "seke seler" hingga memiliki kesamaan rasa dan ikatan batin dan lahir yang sangat kuat. Kemudian pandangan tentang gunung. Selain memandang gunung sebagai sumber utama kehidupan, gunung juga diyakini sebagai salah satu tempat yang memberikan unsur sistem tubuh bagi manusia dalam wujud "sari pati" yang ditanamakan bagian tubuh manusia (Mella Ismelina FR dkk, 2010: 58).

Selain masyarakat Desa Ciomas selalu berpatokan pada daerah aliran sungai (DAS), masyarakat Desa Ciomas selalu memegang teguh adatnya yaitu melakukan ritual yang disebut Nyangku (nyangku berasal dari kata Yangko (bahasa Arab) yang artinya membersihkan). Upacara adat sakral Nyangku merupakan upacara adat warisan dari raja-raja Panjalu yang masih menjadi tradisi yang turun temurun dalam masyarakat Panjalu di antaranya selalu diadakan di desa Ciomas. Pada zaman dahulu upacara adat sakral nyangku merupakan suatu acara ritual yang dianggap agung. Hal ini dikarenakan adanya suatu maksud tertentu dari pada Kerajaan Panjalu sendiri, yaitu sebagai sarana penyebaran agama Islam pada rakyatnya. Upacara adat sakral nyangku biasa diadakan satu kali dalam setahun yaitu pada bulan Rabiul Awal tahun Hijriyah minggu terakhir yang biasa dilaksanakan pada hari senin atau hari kamis. Tujuan dari nyangku pada zaman dahulu adalah untuk membersihkan benda pusaka Kerajaan Panjalu dan sebagai salah satu misi penyebaran agama Islam. Adapun tujuan dari penyelenggaraan upacara 


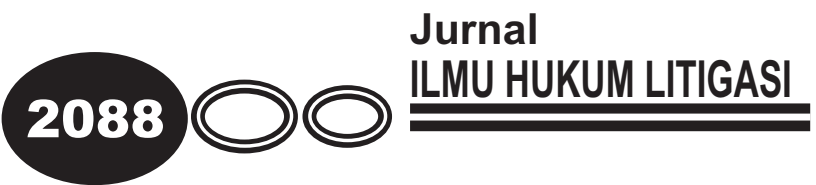

nyangku sekarang hanyalah terbatas membersihkan benda-benda pusaka peninggalan Kerajaan Panjalu, hal ini dikarenakan sudah menyebarnya agama Islam dikalangan masyarakat Panjalu sendiri terlebih-lebih di disekitar daerah Panjalu kebanyakan masyarakat menganut agama Islam termasuk di Desa Ciomas.

Adapun hakekat dari upacara nyangku adalah membersihkan diri dari segala sesuatu yang dilarang oleh agama Islam, upacara nyangku juga bertujuan untuk memperingati Maulid Nabi Muhammad SAW serta untuk mempererat tali persaudaraan masyarakat Panjalu umumnya khususnya masyarakat di Desa Ciomas. Penyelenggaraan upacara adat nyangku dilaksanakan oleh Sesepuh Panjalu dan Pemerintah Desa Panjalu, Para Tokoh, Para Penjaga Makam (kuncen).

Melihat uraian di atas, diberikan pemahaman bahwa kesadaran ekologis hanya akan tumbuh jika memadukan pengetahuan rasional kita dengan intuisi. Kearifan intuitif semacam itu merupakan ciri kebudayaan tradisional. Kebudayaan tradisional tidak melakukan pemisahan antara aspek budaya dan hakekat manusia. 


\section{SIMPULAN DAN SARAN}

\section{A. Simpulan}

1. Interaksi manusia dan lingkungan hidup berdasarkan kearifan budaya Sunda mengacu pada keseimbangan dan keharmonisan lingkungan hidup. Alam dan manusia memiliki hukum ruang dan waktu yang sama atau memiliki substansi yang sama, perbedaannya hanya pada pengaktualisasian yang dilakukan oleh manusia itu sendiri. Manusia merupakan bagian dari keseluruhan unsur lingkungan hidup sehingga keberadaannya mempengaruhi dan dipengaruhi oleh unsur lingkungan hidup lainnya.

2. Konsep pelestarian fungsi lingkungan hidup berdasarkan kearifan budaya Sunda yang lebih menitik beratkan pada relasi dan keseimbangan antara keadilan ekologis dan keadilan sosial, lebih mengakomodasi kesetaraan dan keseimbangan antara kesejahteraan masyarakat dan keharmonisan lingkungan hidup kiranya dapat dijadikan sebagai landasan formulasi model pemberdayaan hukum lingkungan religius-kosmik dan dapat dijadikan landasan bagi perumusan kebijakan dibidang pembangunan hukum lingkungan di Indonesia. 


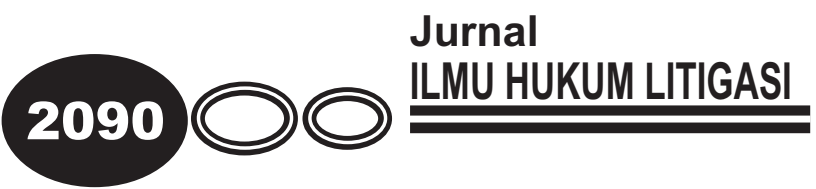

3. Upaya pelestarian fungsi lingkungan hidup di Desa Ciomas Kecamatan Panjalu Kabupaten Ciamis selalu didasarkan pada pandangan filosofi bahwa "Sunda kabagean memeres jaman,"dan aktivitas "ngaberakeun" serta kesadaran dan kemauan untuk menerapkan kembali nilai-nilai pengetahuan luhur melalui implementasi kearifan lokal dalam pengelolaan dan pelestarian fungsi lingkungan hidup.

B. Saran

1. Inventarisasi, sosialisasi dan revitalisasi nilai-nilai kearifan budaya lokal khususnya kearifan budaya Sunda dalam pelestarian fungsi lingkungan hidup perlu terus dilakukan agar pemahaman masyarakat terhadap hal tersebut dapat meningkat dan hasil dari inventarisasi nilai-nilai kearifan budaya lokal dapat dijadikan bahan bagi landasan kebijakan pembangunan hukum lingkungan di Indonesia.

2. Perlu perumusan Hukum Lingkungan yang berkarakteristik ke Indonesiaan dengan berlandaskan pada nilai-nilai budaya lokal di Indonesia. 


\section{DAFTAR PUSTAKA}

Agus Salim, 2001, Teori dan Paradigma Penelitian Sosial dari Denzin Guba dan Penerapannya, PT. Tiara Wacana Yogya, Yogyakarta.

Antonius Birowo, 2004, Metode Penelitian Komunikasi; Teori dan Aplikasi, Gitanyali, Jogyakarta.

Bogdan. Robert C. \& Sari Knopp Biklen, 1982, Qualitative Research for Education; An Introduction to theory and Methods. Allyn and Bacon, Inc. Bostn.

Bogdan. Robert C. \& Taylor Steven J, 1993, Kualitatif; Dasar-Dasar Penelitian, Usaha Nasional Surabaya-Indonesia.

Capra. Fritjof, 2004, Titik Balik Peradaban, Sain, Masyarakat dan kebangkitan Kebudayan, Bentang, Jogyakarta.

Denzin. Norman K. dan Yvonna S. Lincoln, 1994, Introduction: Entering the Field of Qualitative Research, dalam Norman K. Denzin dan Yvonna S. Lincoln, Hand Book of Qualitatif Research,.Sage Publication California.

Janesick. Valerie J., 1994, The Dance of Qualitative Research Design; Metaphor, Methodolartry, and Meaning, dalam Norman K. Denzin dan Yvonna S. Lincoln, Hand Book of Qualitatif Research, Sage Publication, California.

Mella Ismelina FR dkk, 2010, “Model Pembangunan Hukum Lingkungan Berbasis Daerah Aliran Sungai (DAS) Yang Religius-Kosmik Menurut Kearifan Budaya Sunda", Laporan Penelitian Hibah Kompetensi DIKTI, Unisba, Bandung. 


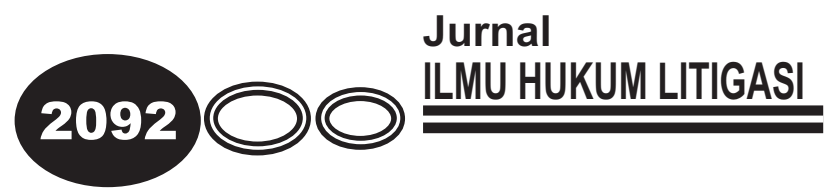

Slamet Sutrisno, 2004, Krisis Pemikiran Modern \& Kawruh Jawa, dalam Agus Purwadianto,Dkk Jalan Paradoks; Visi Baru Fritjof Capra tentang Kearifan dan Kehidupan Modern, Teraju, Mizan,Bandung.

Sonny Keraf, 2002, Etika Lingkungan, Kompas, Jakarta. 